Conf-9505105--1

GA-A22062

\title{
INTERACTION OF FAST WAVES WITH IONS
}

\author{
by \\ S.C. CHIU, J.S. deGRASSIE, R.W. HARVEY, \\ V.S. CHAN, Y.R. LIN-LIU, R.D. STAMBAUGH, \\ H. IKEZI, T.K. MAU, and W.W. HEIDBRINK
}

JUNE 1995 


\section{DISCLAIMER}

Portions of this document may be illegible in electronic image products. Images are produced from the best available original document. 


\title{
INTERACTION OF FAST WAVES WITH IONS
}

\author{
by \\ S.C. CHIU, J.S. deGRASSIE, R.W. HARVEY, \\ V.S. CHAN, Y.R. LIN-LIU, R.D. STAMBAUGH, \\ H. IKEZI, T.K. MAU, ${ }^{*}$ and W.W. HEIDBRINK ${ }^{\dagger}$
}

This is a preprint of a paper presented at the 11th Topical Conference on Radio Frequency Power in Plasmas, May 17-19, 1995, Palm Springs, California, and to be printed in the Proceedings.

\author{
Work supported by \\ U.S. Department of Energy \\ Contract DE-AC03-89ER51114
}

*University of California at San Diego
† University of California at Irvine

GENERAL ATOMICS PROJECT 3466 JUNE 1995 


\title{
Interaction of Fast Waves with Ions
}

\author{
S.C. Chiu, J.S. deGrassie, R.W. Harvey, V.S. Chan, \\ Y.R. Lin-Liu, R.D. Stambaugh, H. Ikezi, T.K. Mau,* \\ and W.W. Heidbrink ${ }^{\dagger}$
}

General Atomics, San Diego, California 92186

* University of California, La Jolla, California 92039

${ }^{\dagger}$ University of California, Irvine, California 92717

\begin{abstract}
To fully utilize the available power sources in DIII-D (FW, NBI, ECH), understanding of the synergism between the heating mechanisms is important. In this paper the ion distribution, under simultaneous application of NBI and FW, is calculated from Fokker-Planck code CQL3D coupled to ray-tracing code CURRAY. It is found that interaction between energetic ions and FW can be minimized or maximized by adjusting various parameters such as magnetic field, density, beam energy, and FW frequency. Specifically, in DIII-D, we find negligible interactions above 1.8 $\mathrm{T}$ and above $80 \mathrm{MHz}$, while the interaction increases at lower fields and frequencies. The results are compared with experiments in DIII-D including the calculated neutron rate. Energetic ion orbit losses may play an important role in the ion distribution, and this effect is being investigated.
\end{abstract}

In order to reach steady- state reactor relevant tokamak parameters, DIII-D will have available various types of power sources for heating $(H)$ and current drive (CD), including $6 \mathrm{MW}$ of fast waves (FW) in the range of 30 to $120 \mathrm{MHz}, 20 \mathrm{MW}$ of neutral beam (NB), and electron cyclotron (EC) waves [1]. To optimize the use of available power, it is natural to consider simultaneous application of the sources. The question then arises as to whether there is any appreciable synergism between the power sources. In this paper, we consider the interactions between FW and the energetic ions produced by NB. 
The ray tracing code CURRAY is used to determine the FW wave fields and polarizations. Typically, about 28 to 42 rays are calculated in the main spectra which are determined from a coupling code V1DARY (coupled to FELICE) [2]. The wave information from CURRAY are input into the bounce averaged Fokker-Planck code CQL3D [3] which calculates the ion distribution in the presence of the of quasilinear diffusion and neutral beam sources on specified flux surfaces. We use typical DIII-D parameters: $B_{0}=1$ to $2 \mathrm{~T}, n_{\mathrm{e}}=1$ to $3 \times 10^{13} / \mathrm{cm}^{3}, T_{\mathrm{e}}=T_{\mathrm{i}}=2$ to $3 \mathrm{keV}$, neutral beam power $P_{\mathrm{b}}=3 \mathrm{MW}$, and $P_{\mathrm{fw}}=1.5 \mathrm{MW}$. An ITER L-mode transport scaling is used to determine the relationship between density and temperature.

In the absence of $\mathrm{rf}$, a slowing down distribution due to NBI is produced. When the if is applied, a large energetic ion tail is developed in CQL3D. This results in enhancement of the absorption of FW by the tail species, and a decrease in electron absorption. The results of parameter scans are summarized in Figs. 1 and 2. It is seen that the ion absorption is decreased by increasing $B$, decreasing $n_{\mathrm{e}}$. This behavior can be qualitatively understood as follows. The perpendicular phase velocity of $\mathrm{FW}$ can be approximated by the Alfvén velocity $v_{A}$, then, the relevant argument of the Bessel function expansion for harmonic absorbed power at the beam energy can be written as

$$
\left(\frac{k_{\perp} u_{\mathrm{b}_{\perp}}}{2 \Omega}\right)^{2} \approx\left(0.073 n_{13} E_{\mathrm{b}} / B^{2}\right) \sin ^{2} \theta
$$

where $n_{13}$ is density in $10^{13} / \mathrm{cm}^{3}, E_{\mathrm{b}}$ is beam energy in $10 \mathrm{keV}, B$ is in tesla,

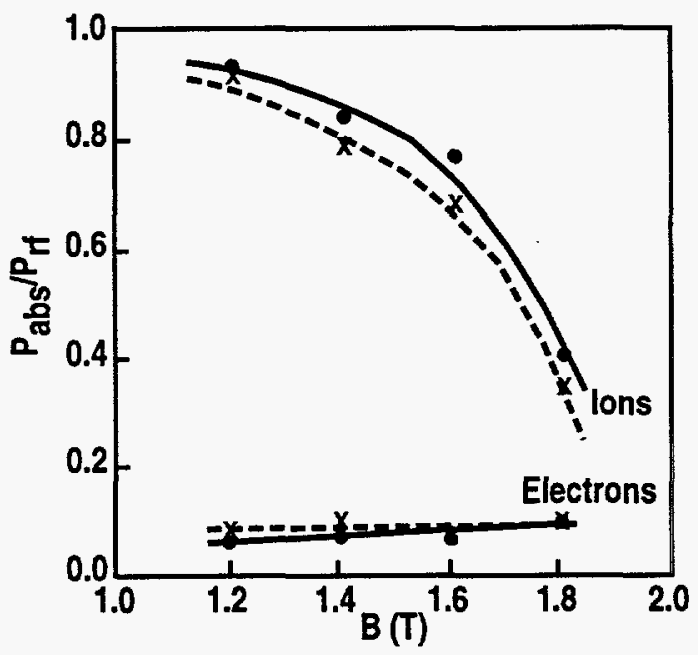

FIGURE 1. Absorption versus B-field; solid line is for $n_{e}=3 \times 10^{13} / \mathrm{cc}, T_{e 0}$ $=2.3 \mathrm{keV}$; dotted line is for $n_{\mathrm{e}}=2 \times 10^{13} / \mathrm{cc}, T_{\mathrm{e} 0}=3.3 \mathrm{keV}, \mathrm{NB}$ power is $3 \mathrm{MW}$; if power is $1.5 \mathrm{MW}$, E-beam is $75 \mathrm{keV}$, if frequency $=60 \mathrm{MHz}$. 


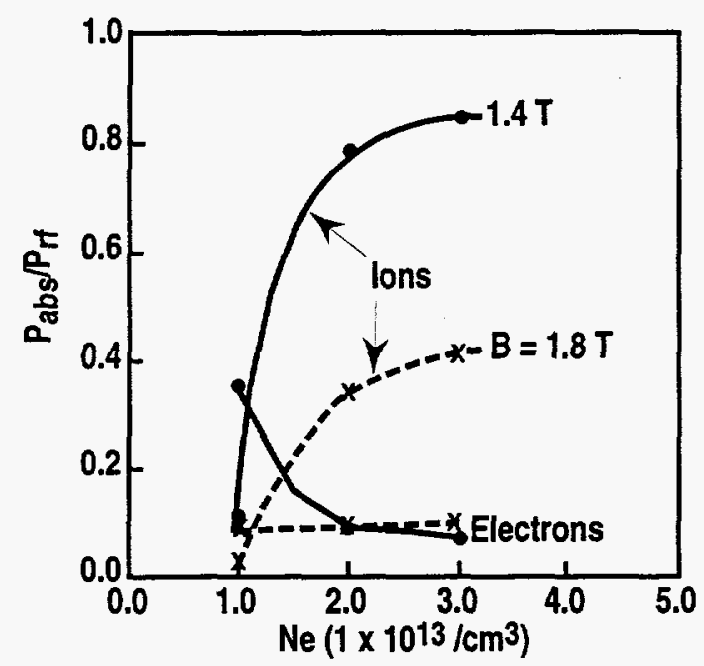

FIGURE 2. Absorption versus average density for two fields; solid line for $B$ $=1.4 \mathrm{~T}$; dotted line for $b=1.8 \mathrm{~T}$; NB and if parameters same as Fig. 3 .

and $\theta$ is pitch angle. At the $\ell$-th harmonic $\ell \approx \omega / \Omega$, the ratio of $\mathrm{rf}$-diffusion to collisional diffusion is roughly given by

$$
\frac{|D|}{\nu_{\mathrm{s}} D_{\mathrm{c}} \mid} \propto \frac{P n_{\mathrm{e}}^{\ell-2.5} E_{\mathrm{b}}^{\ell}}{B^{2 \ell-3} T_{\mathrm{e}}}
$$

Thus for DIII-D parameters where $\ell>4$, the rf-diffusion decreases with decreasing density and beam energy, and with increasing $B$-field. The above were for an rf-power at $60 \mathrm{MHz}$. The interaction is shown to be much weaker at a higher frequency of $80 \mathrm{MHz}$ (Fig. 3).

The neutron rate produced by the energetic ions has been measured with and without rf. We can calculate this rate in CQL3D. Comparison between theory and experiment, however, indicates that the quasilinear theory overestimates the energetic tail produced by rf. One likely origin of the discrepancy is that orbit loss is not taken into account in the calculations. Inclusion of this effect in CQL3D is being implemented and shall be discussed.

In conclusion, the interaction between $\mathrm{NBI}$ and FW is investigated. We find that the interaction can be minimized by reducing the density and beam energy, and by increasing the $B$-field and frequency. At $1.8 \mathrm{~T}$ and $80 \mathrm{MHz}$, the ion absorption becomes small compared with electron absorption. A comparison with experiment, however, indicates that the Fokker-Planck calculation considerably overestimates the energetic ion enhancement. We think a likely source is the neglect of orbit loss in the calculations. 


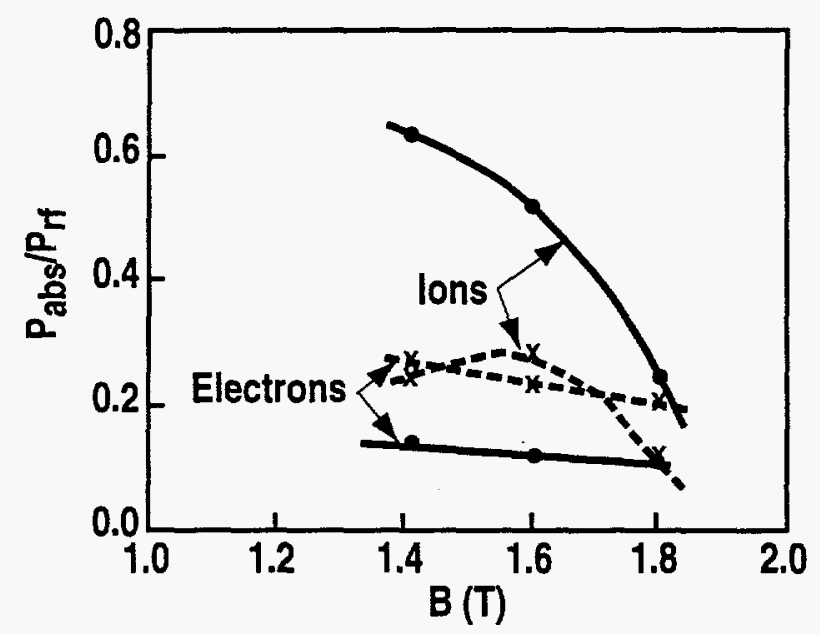

FIGURE 3. Absorption versus B-field for two frequencies; solid line for $f$ $=60 \mathrm{MHz}$, dotted line for $f=80 \mathrm{MHz}$, beam energy is $60 \mathrm{keV}, n_{e}=2 \times 10^{13} / \mathrm{cc}$, $T_{\mathrm{e} 0}=3.3 \mathrm{keV}$.

This is a report of work sponsored by the U.S. Department of Energy under Contract No. DE-AC03-89ER51114.

\section{REFERENCES}

[1] R.D. Stambaugh, "DIII-D Program Overview," to be published in Proc. 15th Int. Conf. on Plasma Physics and Controlled Nuclear Fusion Research, Seville, 1994).

[2] S.C. Chiu, M.J. Mayberry, and W.D. Bard, Nucl. Fusion 20, 2551 (1990).

[3] R.W. Harvey and M.G.McCoy, in Proc. IAEA TCM on Advances in Simulation and Modeling of Thermonuclear Plasmas, Montreal, 1992, p. 489. 


\section{DISCLAIMER}

This report was prepared as an account of work sponsored by an agency of the United States Government. Neither the United States Government nor any agency thereof, nor any of their employees, make any warranty, express or implied, or assumes any legal liability or responsibility for the accuracy, completeness, or usefulness of any information, apparatus, product, or process disclosed, or represents that its use would not infringe privately owned rights. Reference herein to any specific commercial product, process, or service by trade name, trademark, manufacturer, or otherwise does not necessarily constitute or imply its endorsement, recommendation, or favoring by the United States Government or any agency thereof. The views and opinions of' authors expressed herein do not necessarily state or reflect those of the United States Government or any agency thereof. 